\section{BRAZIULAN JOURNAL \\ OF MEDICAL AND BIOLOGICAL RESEARCH}

www.bjournal.com.br
ISSN 1414-431X

Volume 45 (12) 1102-1340 December 2012

\section{BIOMIDICAL SCIENCES}

AND

CLINICAL INVESTIGATION

Braz J Med Biol Res, December 2012, Volume 45(12) 1112-1118

doi: $10.1590 / \mathrm{S} 0100-879 \mathrm{X} 2012007500130$

\title{
Overexpression of Fc receptor-like 1 associated with B-cell activation during hepatitis $\mathrm{B}$ virus infection
}

Ke Wang, Hao Pei, Biao Huang, Run-Lin Yang, Hang-Yuan Wu, Xue Zhu and Lan Zhu

The Brazilian Journal of Medical and Biological Research is partially financed by

\section{욛NPq}

da Ciência e Tecnologia

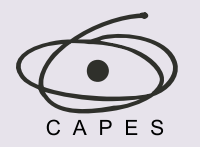

Ministério da Educação
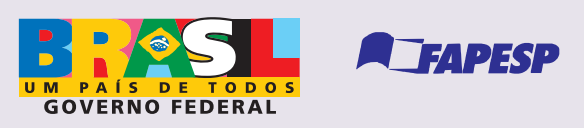

Institutional Sponsors

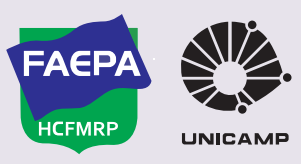

$\oplus$ SHIMADZu

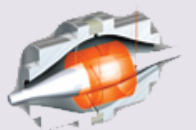

UNICAMP

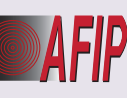

Explore High - Performance MS Orbitrap Technology scielo
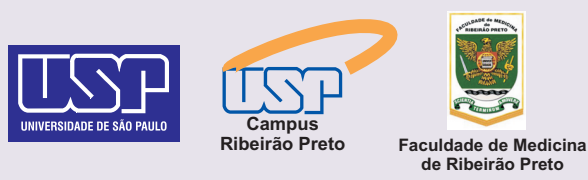

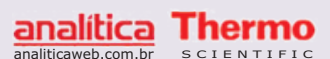




\title{
Overexpression of Fc receptor-like 1 associated with B-cell activation during hepatitis $B$ virus infection
}

\author{
Ke Wang ${ }^{1}$, Hao $\mathrm{Pei}^{2}$, Biao Huang ${ }^{1}$, Run-Lin Yang ${ }^{1}$, Hang-Yuan $\mathrm{Wu}^{2}$, \\ Xue Zhu ${ }^{1}$ and Lan Zhu ${ }^{1}$ \\ ${ }^{1}$ Key Laboratory of Nuclear Medicine, Ministry of Health, Jiangsu Key Laboratory of Molecular Nuclear Medicine, \\ Jiangsu Institute of Nuclear Medicine, Wuxi, Jiangsu Province, China \\ 2Wuxi Hospital of Infectious Disease, Wuxi, Jiangsu Province, China
}

\begin{abstract}
The role of $B$ cells in the pathogenesis of hepatitis B virus (HBV) infection has not been explored in depth. In the present study, the activation status of $B$ cells from peripheral blood of healthy controls $(N=20)$ and patients with acute hepatitis $B(A H B, N=$ $15)$ or chronic hepatitis $B(C H B, N=30)$ was evaluated by measuring the expression levels of $B$-cell activation markers $C D 69$ and CD86, using quantitative real-time PCR and flow cytometry. Moreover, the potential mechanism underlying B-cell activation during HBV infection was further investigated by analyzing the expression profile of FCRL1, an intrinsic activation molecule of B cells. An elevation in the levels of B-cell activation markers including CD69 and CD86 was observed in the AHB patients $(44.31 \pm 9.27,27.64 \pm 9.26 \%)$ compared to CHB patients $(30.35 \pm 11.27,18.41 \pm 6.56 \%, P<0.05)$, which was still higher than healthy controls $(12.23 \pm 7.84,8.22 \pm 3.43 \%, \mathrm{P}<0.05)$. Furthermore, the expression of FCRL1 was found to be similar to $\mathrm{B}$-cell activation markers, which was highest in AHB patients $(70.15 \pm 17.11 \%)$, lowest in healthy donors $(36.32 \pm 9.98 \%, P<0.05)$ and half-way between these levels in patients with $\mathrm{CHB}(55.17 \pm 12.03 \%, \mathrm{P}<0.05)$. The results were positively associated with aberrant B-cell activation. These data suggest that B cells can play a role in HBV infection, and therefore more effort should be devoted to exploring their functions.
\end{abstract}

Key words: Hepatitis B virus; B-cell activation; Fc receptor-like 1; Gene expression

\section{Introduction}

Hepatitis $B$ virus (HBV) is the most common cause of liver disease worldwide (1). It is estimated that two billion people have been infected with HBV and more than 350 million suffer chronic liver infections. About $5 \%$ of adult patients with acute $\mathrm{HBV}(\mathrm{AHB})$ infection may develop chronic hepatitis $B(\mathrm{CHB})$ infection $(2,3)$. HBV infection can cause necroinflammation that with time can progress to hepatic fibrosis, cirrhosis and even hepatocellular carcinoma (4-6). Extensive investigations have focused on the mechanisms of HBV-specific T-cell dysfunction, whereas B-cell dysfunction during HBV infection has been less studied $(7,8)$. Previous studies have found that HBV antigen binds to $B$ cells in vitro, resulting in B-cell activation through a T-celldependent or T-cell-independent pathway. However, studies on the activation status of B cells in HBV-infected patients are not available (9-11).
The understanding of the B-cell activation mechanisms has been advanced by identification of Fc receptor-like 1 (FCRL1), also known as FCRH1 $(12,13)$. FCRL1 is a member of the Fc receptor homologue family encoded by a gene on chromosome 1q21-23 and preferentially expressed in B cells (14-16). This molecule has two immunoreceptor tyrosine-based activation motifs (ITAM-like motifs), suggesting that it may play a key role in B-cell activation. Compelling evidence indicates that FCRL1 is an intrinsic activation molecule that has the potential to amplify B-cell antigen receptor-induced activation. Abnormal expression of FCRL1 has been reported in diseases such as chronic lymphocytic leukemia, hairy cell leukemia and B-cell nonHodgkin lymphoma, but its particular role in the progression of the HBV infection remains unknown $(17,18)$.

In the present study, the activation status of B cells

Correspondence: Biao Huang, Key Laboratory of Nuclear Medicine, Jiangsu Institute of Nuclear Medicine, No. 20 Qianrong Street, Wuxi 214063, Jiangsu Province, China. Fax: +86-510-8552-0070. E-mail: cluseee@hotmail.com

Received March 6, 2012. Accepted August 3, 2012. Available online August 17, 2012. Published December $17,2012$. 
was studied in human peripheral blood lymphocytes from AHB- or CHB-infected individuals by analyzing the expression profiles of B-cell activation markers including CD69 and CD86. The expression level of FCRL1, an intrinsic activation molecule of $B$ cells, and its correlation with the activation status of $B$ cells during HBV infection were also investigated. An attempt was made to elucidate the role of B lymphocytes in HBV-induced disease progression.

\section{Patients and Methods}

\section{Patients}

The study was approved by the Ethics Committee of Wuxi Hospital of Infectious Disease and Jiangsu Institute of Nuclear Medicine. All donors gave written informed consent to donate blood. Sixty-five subjects were recruited from Wuxi Hospital of Infectious Disease between 2009 and 2010, 20 were healthy donors, 15 were AHB patients and 30 were $\mathrm{CHB}$ patients. Patients with autoimmune hepatitis or hepatitis $\mathrm{C}$ virus (HCV) co-infection were excluded from the study by screening with HCV and antinuclear antibodies. None of the patients had been treated with antiviral agents during a 12-month period before enrollment in the study.

\section{Cell isolation}

Peripheral blood mononuclear cells (PBMC) were separated by Ficoll density centrifugation (Cedarlane Labs, USA) as mentioned before (12). B lymphocytes were further purified from PBMC by negative selection with magnetic beadconjugated antibody (StemCell, Canada). The homogeneity of cells was confirmed by flow cytometry (>95\%).

\section{Quantitative real-time polymerase chain reaction (RT-PCR)}

Total RNA was extracted from purified B lymphocytes with Trizol and first-strand CDNA was obtained with the PrimeScript ${ }^{\mathrm{TM}} \mathrm{RT}$ reagents Kit (Takara, Japan). RT-PCR was performed using SYBR green PCR Master Mix (Takara) with the ABI PRISM 7700 detection system. Primers for this study were designed using the Primer Express Software version 2.0 (Table 1). To assure specific amplification, the melting curves of each reaction were monitored and each sample was processed in duplicate. Human glyceraldehyde-3-phosphate dehydrogenase was included as the housekeeping gene. Relative quantification of the target gene expression was analyzed using the Q-Gene software.

\section{Flow cytometry}

All blood samples were processed on the day of collection. PerCP-conjugated antiCD19, FITC-conjugated anti-CD69 or antiCD86 and FITC-conjugated anti-FCRL1 [BD Biosciences (USA) and R\&D Systems (USA)] were used to evaluate the activation status of $B$ cells and FCRL1-positive B cells, respectively. After staining, cells were resuspended in fluorescence-activated cell sorting solution, fixed in $1 \%$ paraformaldehyde and analyzed with the FACS Calibur system (BD Pharmingen, USA).

\section{Statistical analysis}

Data are reported as means $\pm S D$. The unpaired Student $t$-test and the chi-square test were used for data analysis. A $P$ value of $<0.05$ was considered to be statistically significant. The analyses were performed using the SPSS 15.0 software (USA).

\section{Results}

\section{Clinical characteristics of the groups studied}

Three groups of subjects were included in the present study (Table 2). The first consisted of 20 health controls with no evidence of any liver diseases and with negative tests for HBV markers. The second consisted of 15 patients diagnosed with $\mathrm{AHB}$ and with no history of chronic liver disease. The third consisted of 30 patients who had been HBsAg-positive for more than 6 months and whose clinical appearance showed active CHB. Patient age and gender data and biochemical tests for serum bilirubin, albumin, aspartate aminotransferase and alanine transaminase were also obtained.

\section{Activation status of B cells in HBV-induced diseases}

To explore the activation status of $B$ cells from healthy controls and HBV patients, the expression profiles of B-cell surface markers, including early lymphocyte activation marker CD69 and co-stimulatory molecule CD86, were analyzed by real-time PCR and flow cytometry. As shown in Figure 1, B cells from HBV-infected patients had relatively higher mRNA expression levels of CD69 and CD86 compared to those from healthy donors $(P<0.05)$ and AHBinfected individuals exhibited a much higher level than the CHB group ( $P<0.05)$. The frequency of CD69 and CD86 protein expression from 65 samples was examined by flow

Table 1. Primers used to measure the relative gene expression by RT-qPCR.

\begin{tabular}{lllc}
\hline Genes & Primers & \multicolumn{1}{c}{ Sequences (5'-3') } & Amplicon size (bp) \\
\hline CD69 & CD69-F & TGGTGATGAAGACCACATTCA & 129 \\
& CD69-R & AGAACAGCTCTTTGCATCCG & \\
CD86 & CD86-F & AGAGGAGCAGCACCAGAGAG & 125 \\
& CD86-R & ATGAGTGGGGTCATTTCCAG & \\
FCRL1 & FCRL1-F & CCTACCTCAACTCACCTAC & 127 \\
& FCRL1-R & TCTGCTGCTACTGATTCC & \\
GAPDH & GAPDH-F & AACAGCCTCAAGATCATCAGC & 199 \\
& GAPDH-R & GGATGATGTTCTGGAGAGCC & \\
\hline
\end{tabular}

$F=$ forward $R$ = reverse. 
cytometry. Representative plots of CD69 and CD86 expression in CD19 B cells from PBMC of 1 healthy donor, $1 \mathrm{AHB}$ patient and $1 \mathrm{CHB}$ patient are shown in Figure 2A. Compared to healthy controls (12.23 \pm $7.84,8.22 \pm 3.43 \%$ ), a higher frequency of expression was observed in AHB patients (44.31 \pm 9.27 , $27.64 \pm 9.26 \%)$ and $\mathrm{CHB}$ patients $(30.35 \pm 11.27$, $18.41 \pm 6.56 \%)$ and there was also a significant difference between the two patient groups $(P<0.05$; Figure 2B). In addition, the protein expression level of these molecules was significantly correlated with their corresponding mRNA expression level (data not shown).

\section{FCRL1 is up-regulated in B cells from HBV- infected patients}

The expression profiles of FCRL1 in B cells from healthy controls and HBV-infected patients were also analyzed using real-time PCR and flow cytometry. The results revealed that, compared to healthy controls, on average, FCRL1 mRNAexpression was 18-fold higher in AHB and 8-fold higher in CHB ( $\mathrm{P}<0.05$; Figure 3$)$. In addition, the variance was significant different among the patients of the two groups $(P<0.05)$. The protein expression level of FCRL1 in B cells from the three groups was also evaluated. As shown in Figure 4, the level of FCRL1 expression was highest in AHB patients (70.15 \pm $17.11 \%)$, lowest in healthy donors (36.32 $\pm 9.98 \%$ ) and half-way between these levels in patients with CHB (55.17 $\pm 12.03 \%$; $P<0.05)$. Overall, the protein expression pattern was similar to that obtained by real-time PCR.

\section{Correlation between FCRL1 expression and activation status of $B$ cells}

The PBMC employed in these experiments were simultaneously used to examine the expression levels of B-cell activation markers and FCRL1. Up-regulation of FCRL1 was then associated with the up-regulation of B-cell activation markers including $\mathrm{CD} 69\left(\mathrm{R}^{2}=0.708 ; \mathrm{P}<0.05\right)$ as well as CD86 $\left(R^{2}=0.740, P<0.05\right)$ by correlation analysis. These findings indicated that the protein expression level of FCRL1 in the total CD19 B cells is positively correlated with the activation status of $\mathrm{B}$ cells in $\mathrm{HBV}$-induced progression (Figure 5).

\section{Discussion}

The mechanism of HBV infection is not clear and previous studies have focused on virus-specific T-cell immune responses $(7,8)$. B cells, important antigen-presenting cells, also may play an important role in HBV infection $(19,20)$. Some data suggest that abnormal B-cell activation may be involved in the process of immune responses to HBV
Table 2. Clinical characteristics of the subjects enrolled in the study.

\begin{tabular}{lccc}
\hline Parameters & $\mathrm{HC}(\mathrm{N}=20)$ & $\mathrm{AHB}(\mathrm{N}=15)$ & $\mathrm{CHB}(\mathrm{N}=30)$ \\
\hline Age (years) & $34.2 \pm 8.3$ & $30.5 \pm 4.3$ & $42.5 \pm 8.3$ \\
Gender (M/F) & $14 / 6$ & $10 / 5$ & $19 / 11$ \\
Serum bilirubin $(\mathrm{mg} / \mathrm{mL})$ & $0.4 \pm 0.4$ & $10.5 \pm 9.2$ & $1.4 \pm 6.1$ \\
Albumin (g/dL) & $4.5 \pm 1.9$ & $5.4 \pm 3.8$ & $4.3 \pm 2.8$ \\
AST (IU/L) & $19.4 \pm 4.2$ & $496.6 \pm 145.3$ & $46.0 \pm 57.1$ \\
ALT (IU/L) & $16.3 \pm 3.8$ & $1199.8 \pm 628.2$ & $98.8 \pm 62.3$ \\
\hline
\end{tabular}

$\mathrm{HC}=$ healthy controls; $\mathrm{AHB}=$ acute hepatitis $\mathrm{B} ; \mathrm{CHB}=$ chronic hepatitis $\mathrm{B}$; $\mathrm{AST}=$ aspartate aminotransferase; $\mathrm{ALT}=$ alanine transaminase.
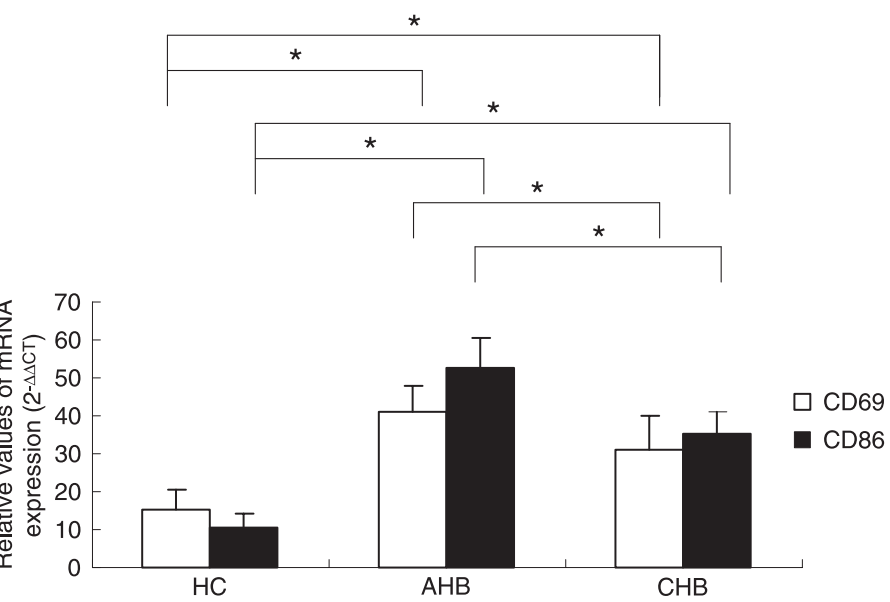

Figure 1. mRNA expression profiles of B-cell activation markers including CD69 and CD86 in B lymphocytes from peripheral blood of healthy controls $(\mathrm{HC})$ and of patients with acute hepatitis $B(A H B)$ and chronic hepatitis $\mathrm{B}(\mathrm{CHB})$. ${ }^{*} \mathrm{P}<0.05$ for the comparisons indicated by the horizonal bars (unpaired Student $t$-test).

antigen (21). To determine the activation status of peripheral blood B cells from HBV patients, the expression profiles of activation markers including CD69 and CD86 were examined in circulating $B$ cells of patients, being considered to be nearly absent from circulating B cells of healthy controls. The expression profile of FCRL1, a key molecule in the activation pathway of B cells, was also assessed.

In the present study, we collected 65 samples from 20 healthy donors, 15 patients with AHB infection and 30 patients with active $\mathrm{CHB}$ infection. The percentage of CD19 B cells did not differ significantly between healthy controls and the two patient groups (data not shown). Higher expression levels of the early lymphocyte activation marker CD69 and the co-stimulatory molecule CD86 in B cells isolated from patients with HBV infection suggested that an increased B-cell activation status may play an important role during HBV infection. Moreover, we observed an increase in the fraction of positive cells after the acute phase of infection, compared to the active chronic phase of infection. This 
A
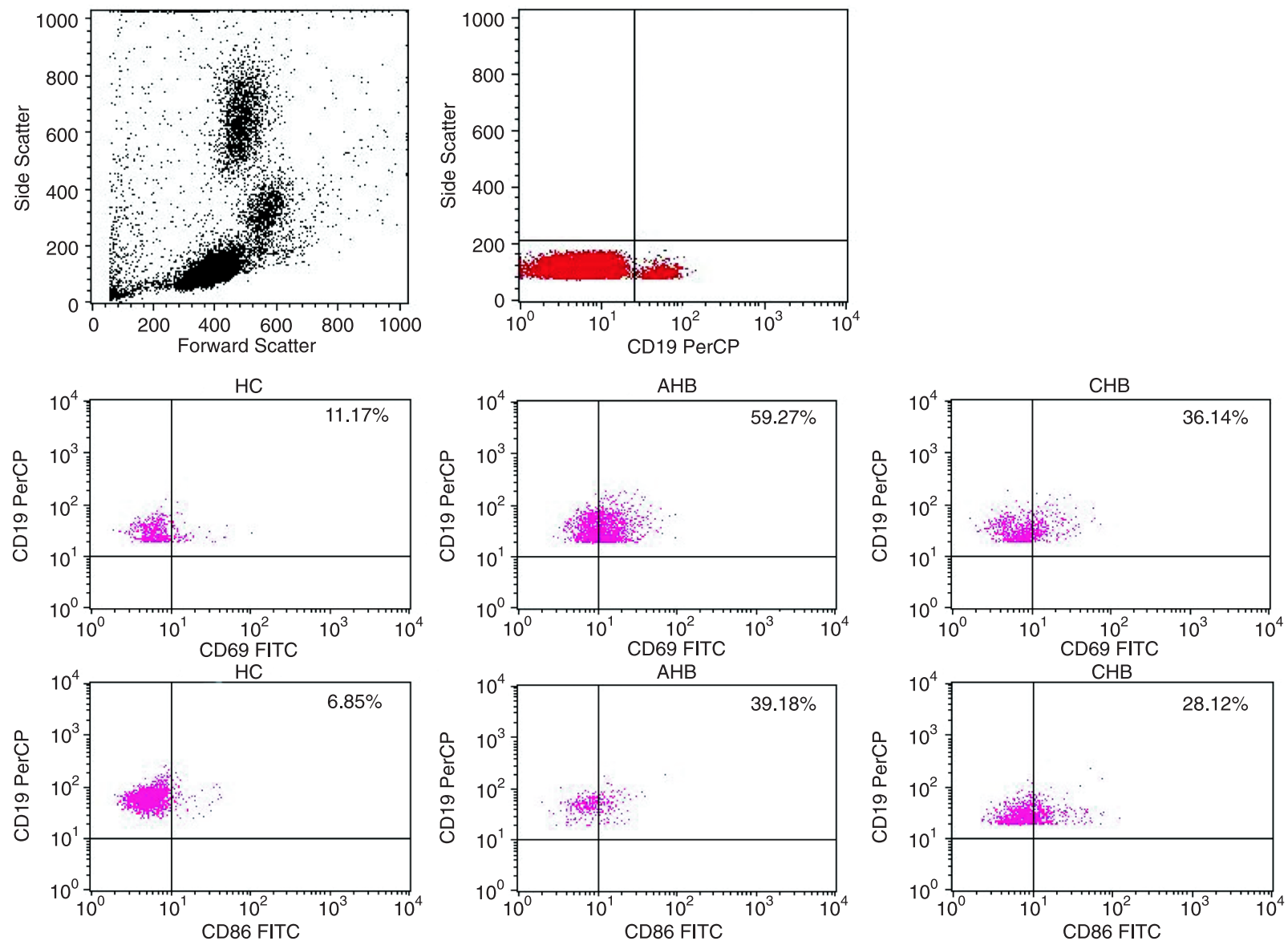

B
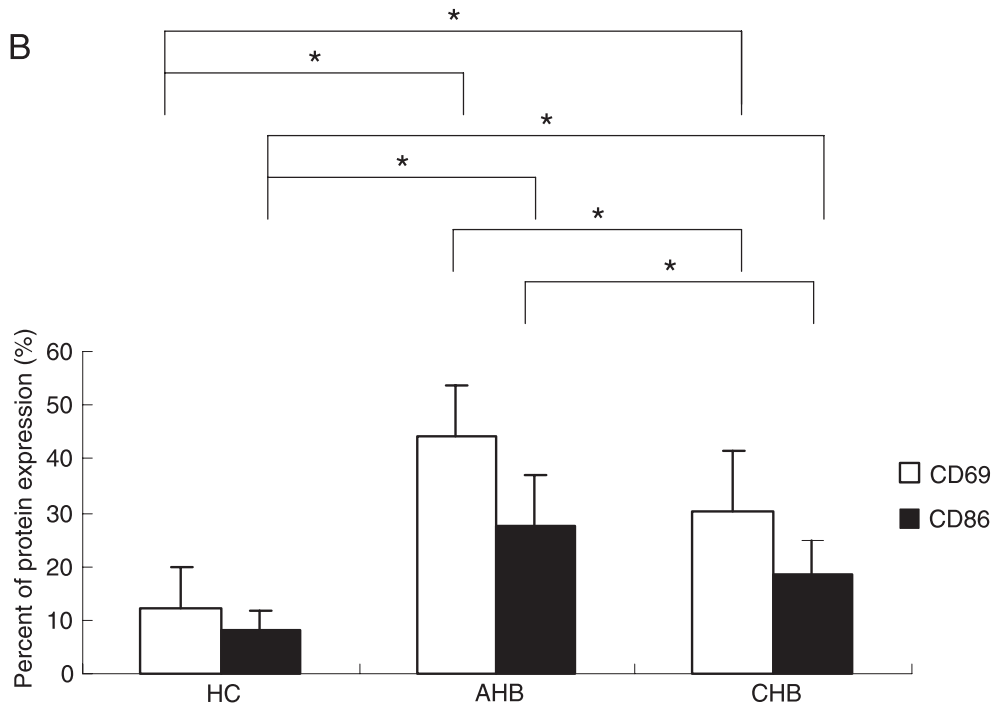

Figure 2. Protein expression profiles of $B$-cell activation markers including CD69 and CD86 in $B$ lymphocytes from peripheral blood of healthy controls $(\mathrm{HC})$ and of patients with acute hepatitis $B(\mathrm{AHB})$ and chronic hepatitis $\mathrm{B}(\mathrm{CHB})$. A, Flow cytometry analysis of a $\mathrm{HC}$, an $\mathrm{AHB}$ patient and a CHB patient. $B$, Statistical analysis of the three groups. ${ }^{*} \mathrm{P}<0.05$ for the comparisons indicated by the horizontal bars (unpaired Student $t$-test). 


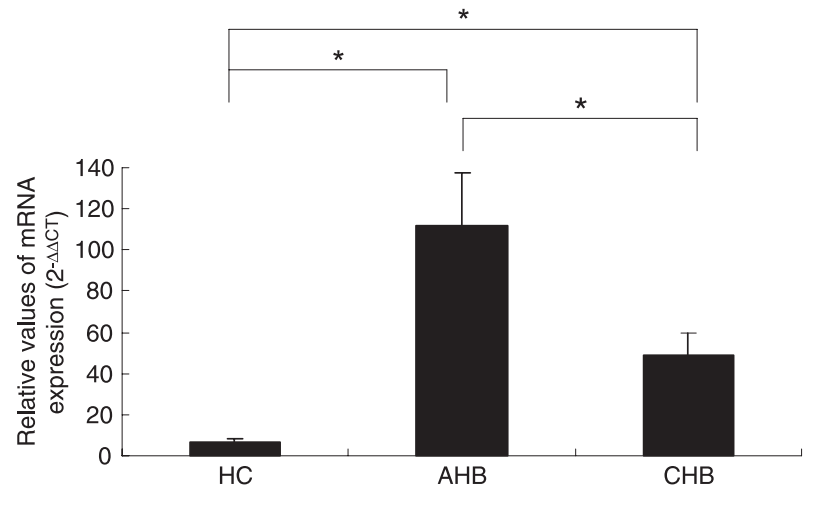

Figure 3. mRNA expression profile of FCRL1 in B lymphocytes from peripheral blood of healthy controls $(\mathrm{HC})$ and of patients with acute hepatitis $B(\mathrm{AHB})$ and chronic hepatitis $\mathrm{B}(\mathrm{CHB}){ }^{*} \mathrm{P}$ $<0.05$ for the comparisons indicated by the horizontal bars (unpaired Student $t$-test).
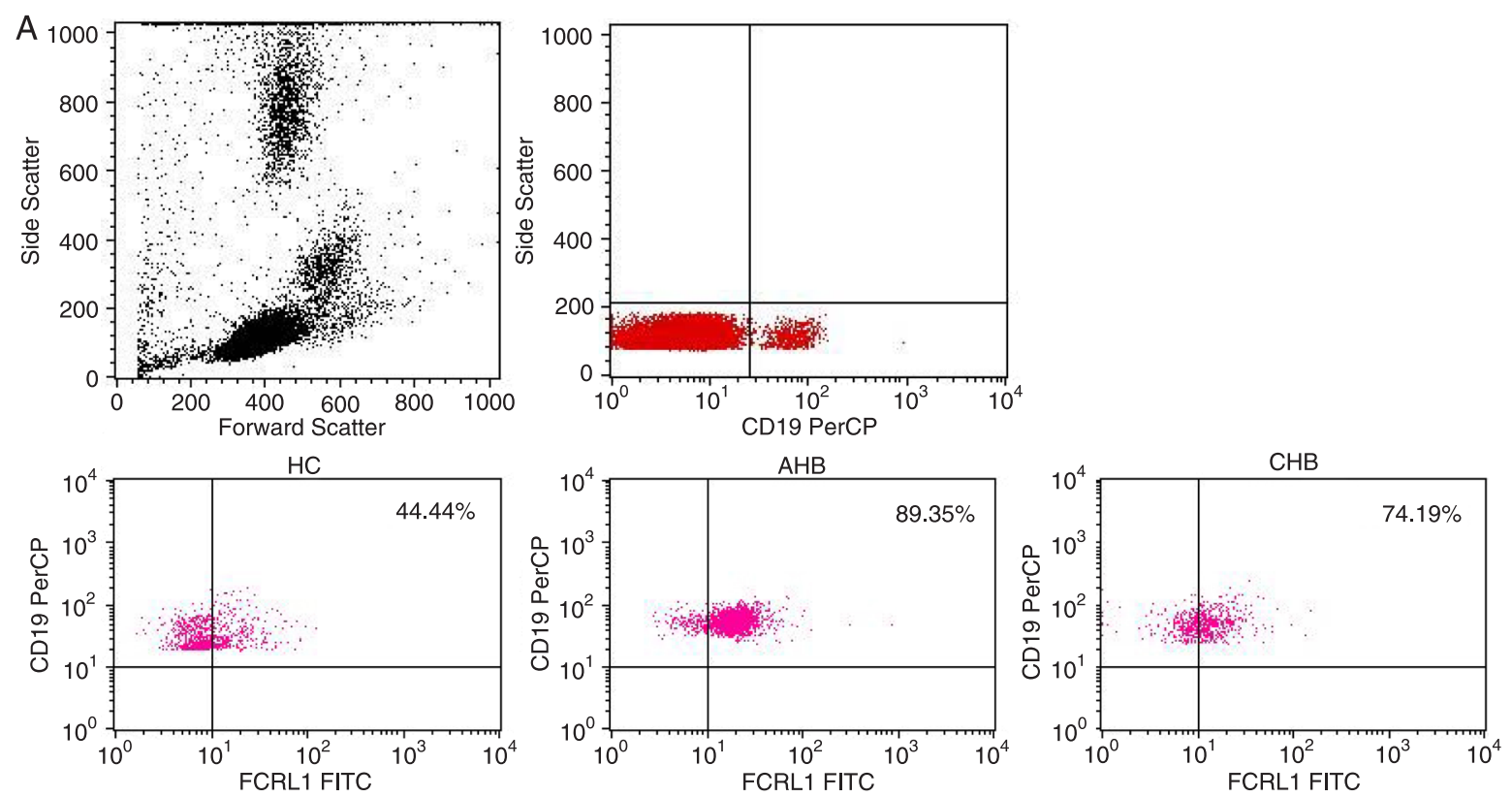

B
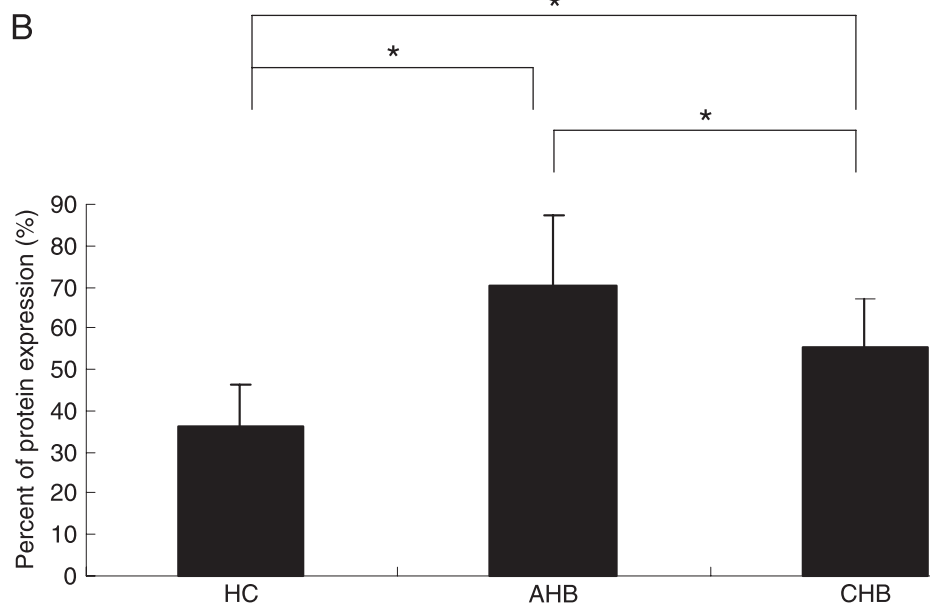

Figure 4. Protein expression profile of FCRL1 in $B$ lymphocytes from peripheral blood of healthy controls (HC) and of patients with acute hepatitis $B(\mathrm{AHB})$ and chronic hepatitis B (CHB). A, Flow cytometry analysis of a HC, an AHB patient and a CHB patient. B, Statistical analysis of the three groups. ${ }^{*} \mathrm{P}<0.05$ for the comparisons indicated by the horizontal bars (unpaired Student $t$-test). 
dynamic modulation of the antiviral immune response via activation of $B$ lymphocytes might support the healing process at the site of acute infection. Previous studies have also reported that the majority of acute virus-infected patients exhibited activated B cells, but few data have been reported about the difference in B-cell activation status between patients with acute and chronic infection (22). Our results indicated that HBV-infected subjects who developed acute hepatitis showed a much stronger B-cell response to the virus than did the chronic cases.

The mechanisms underlying B-cell activation during HBV infection have been further investigated in our study. Previous studies have reported that FCRL1, an intrinsic activation molecule in B cells, was found in all the circulating $B$ cells and showed a much higher expression than activation markers including CD69 and CD86 $(12,23)$. Our results indicated that FCRL1 was highest in AHB patients, lowest in healthy donors and half-way between these two extremes in patients with $\mathrm{CHB}$. The mean values were significantly different among the three groups. In addition, up-regulation of FCRL1 was positively correlated with the corresponding up-regulation of activation markers. The biological meaning of this overexpression deserves careful interpretation and additional investigation. It may represent a pathogenic phenomenon of activated $B$ cells that overexpress FCRL1 or an intrinsic factor that stimulates aberrant B-cell activation.

A relationship between abnormal $B$-cell activation and FCRL1 overexpression is evident, but how this regulatory pathway acts in the development of acute and chronic HBV infection is unknown. Further study is needed to investigate the cellular and molecular basis of this phenomenon. The understanding of this mechanism might be helpful for the
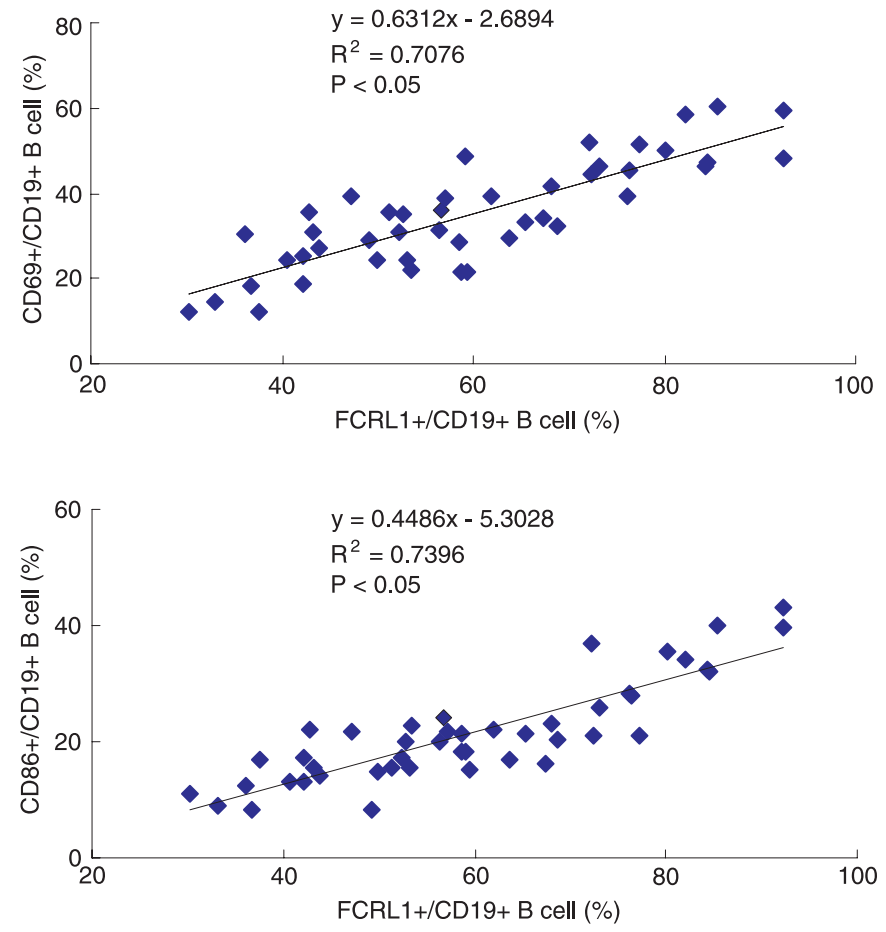

Figure 5. Positive correlation between the expression levels of FCRL1 and B-cell activation markers including CD69 and CD86 in B cells from patients with acute hepatitis $B(A H B)$ and chronic hepatitis $B(C H B)$ (correlation analysis).

treatment of this disease.

\section{Acknowledgments}

The authors are very grateful to the Natural Science Foundation of Jiangsu Province (\#BK2011168).

\section{References}

1. Te HS, Jensen DM. Epidemiology of hepatitis B and C viruses: a global overview. Clin Liver Dis 2010; 14: 1-21, vii.

2. Lledo JL, Fernandez C, Gutierrez ML, Ocana S. Management of occult hepatitis B virus infection: an update for the clinician. World J Gastroenterol 2011; 17: 1563-1568.

3. Vierling JM. The immunology of hepatitis B. Clin Liver Dis 2007; 11: 727-viii.

4. Chisari FV, Isogawa M, Wieland SF. Pathogenesis of hepatitis B virus infection. Pathol Biol 2010; 58: 258-266.

5. Ni YH. Natural history of hepatitis $B$ virus infection: pediatric perspective. J Gastroenterol 2011; 46: 1-8.

6. Nguyen VT, Law MG, Dore GJ. Hepatitis B-related hepatocellular carcinoma: epidemiological characteristics and disease burden. J Viral Hepat 2009; 16: 453-463.

7. Bertoletti $A$, Maini MK, Ferrari $C$. The host-pathogen interaction during HBV infection: immunological controversies. Antivir Ther 2010; 15 (Suppl 3): 15-24.

8. Jung MC, Pape GR. Immunology of hepatitis B infection.
Lancet Infect Dis 2002; 2: 43-50.

9. Milich DR, Chen M, Schodel F, Peterson DL, Jones JE, Hughes JL. Role of $B$ cells in antigen presentation of the hepatitis B core. Proc Natl Acad Sci U S A 1997; 94: 1464814653.

10. Lazdina U, Alheim M, Nystrom J, Hultgren C, Borisova G, Sominskaya I, et al. Priming of cytotoxic $T$ cell responses to exogenous hepatitis B virus core antigen is B cell dependent. J Gen Virol 2003; 84: 139-146.

11. Lazdina U, Cao T, Steinbergs J, Alheim M, Pumpens $P$, Peterson DL, et al. Molecular basis for the interaction of the hepatitis $B$ virus core antigen with the surface immunoglobulin receptor on naive B cells. J Virol 2001; 75: 6367-6374.

12. Leu CM, Davis RS, Gartland LA, Fine WD, Cooper MD. FcRH1: an activation coreceptor on human B cells. Blood 2005; 105: 1121-1126.

13. Du X, Nagata S, Ise $T$, Stetler-Stevenson M, Pastan I. FCRL1 on chronic lymphocytic leukemia, hairy cell leuke- 
mia, and B-cell non-Hodgkin lymphoma as a target of immunotoxins. Blood 2008; 111: 338-343.

14. Mechetina LV, Najakshin AM, Volkova OY, Guselnikov SV, Faizulin RZ, Alabyev BY, et al. FCRL, a novel member of the leukocyte $\mathrm{Fc}$ receptor family possesses unique structural features. Eur J Immunol 2002; 32: 87-96.

15. Ehrhardt GR, Leu CM, Zhang S, Aksu G, Jackson T, Haga C, et al. Fc receptor-like proteins (FCRL): immunomodulators of B cell function. Adv Exp Med Biol 2007; 596: 155-162.

16. Davis RS. Fc receptor-like molecules. Annu Rev Immunol 2007; 25: 525-560

17. Kazemi $\mathrm{T}$, Asgarian-Omran $\mathrm{H}$, Memarian $\mathrm{A}$, Shabani $\mathrm{M}$, Sharifian RA, Vossough P, et al. Low representation of Fc receptor-like 1-5 molecules in leukemic cells from Iranian patients with acute lymphoblastic leukemia. Cancer Immunol Immunother 2009; 58: 989-996.

18. Kazemi T, Asgarian-Omran $\mathrm{H}$, Hojjat-Farsangi $M$, Shabani M, Memarian A, Sharifian RA, et al. Fc receptor-like 1-5 molecules are similarly expressed in progressive and indolent clinical subtypes of B-cell chronic lymphocytic leukemia. Int
J Cancer 2008; 123: 2113-2119.

19. Farci P, Diaz G, Chen Z, Govindarajan S, Tice A, Agulto L, et al. $B$ cell gene signature with massive intrahepatic production of antibodies to hepatitis B core antigen in hepatitis B virus-associated acute liver failure. Proc Natl Acad Sci U S A 2010; 107: 8766-8771.

20. Wu C, Liu Y, Zhao Q, Chen G, Chen J, Yan X, et al. Soluble CD40 ligand-activated human peripheral $B$ cells as surrogated antigen presenting cells: A preliminary approach for anti-HBV immunotherapy. Virol J 2010; 7: 370.

21. Oliviero B, Cerino A, Varchetta S, Paudice E, Pai S, Ludovisi $S$, et al. Enhanced B-cell differentiation and reduced proliferative capacity in chronic hepatitis $C$ and chronic hepatitis $B$ virus infections. J Hepatol 2011; 55: 53-60.

22. Bachmann MF, Kopf M. The role of B cells in acute and chronic infections. Curr Opin Immunol 1999; 11: 332-339.

23. Llinas L, Lazaro A, de Salort J, Matesanz-Isabel J, Sintes J, Engel P. Expression profiles of novel cell surface molecules on B-cell subsets and plasma cells as analyzed by flow cytometry. Immunol Lett 2011; 134: 113-121. 